\title{
PRODUCTION OF CHITOSAN FROM SHRIMP SHELLS BY MICROWAVE TECHNIQUE AND ITS USE IN MINCED BEEF PRESERVATION
}

\author{
Neama A. Omara, Essam M. Elsebaie*, H. E. Kassab, A. A. Salama
}

Department of Food Technology, Faculty of Agricultural, Kafrelsheikh University, P. B. 33516, Kafrelsheikh, Egypt

*Corresponding author, E-mail: essam.ahmed@agr.kfs.edu.eg; http://orcid.org/0000-0002-85070694

\begin{abstract}
This work was undertaken to figure out the optimum conditions for transformation of chitin to chitosan via microwave and to determine chitosan physical properties, antioxidant and antimicrobial activities to evaluate the possibility of using such by-products in preparing some functional foods. The obtained results revealed that deacetylation degree (DA) $93 \%$ attained by chitin remediation with $50 \%$ aqueous sodium hydoxide sol at 1:25 solid:liquid ratio for 10 min into a microwave using a power $800 \mathrm{~W}$. Purified chitosan was characterized for molecular weight (4200 KDa), solubility (94\%), water holding capacity (505\%), oil holding capacity (321\%) as well as intrinsic viscosity $(13.2 \mathrm{dl} / \mathrm{g})$. Samples of meat containing chitosan $(0.02 \%)$ have the minimal experiment into the microbiological count, e.g. total count, yeasts and moulds. The anti-microbial effectiveness of chitosan was frequently higher than that of sorbistat-K or their blend by adding $0.01 \%$ chitosan and the same percent from sorbistat-K. Sensual attributes of samples contained chitosan, i.e. odour, texture and colour, were greater than other samples (sorbistat-K and control treatments). Though, chitosan nominated like a potent, eco-friendly and naturalistic substitution to reserve meat and protect its comprehensive quality.
\end{abstract}

Key words: chitosan; microwave; antioxidant activity; natural preservative

\section{Introduction}

Artificial anti-oxidative substances like butylated hydroxyanisole (BHA) and butylated hydroxytoluene (BHT) were utilized to hold up oxidation of lipids in meat (1). Nonetheless, contemporary attention over their utilization has generated a necessity and induced research for alternate antioxidants, predominately from naturalistic origin. The usage of naturalistic preservatives with meat products increases the storage shelf life is a hopeful technology as nu- merous vegetative materials posse antimicrobial and antioxidant characteristics (2). Functional substances supplement into meat products might upgrade the health and nutritional attributes and extension their storage shelf-life (3).

The meat industry is rottenly suffering from many critical challenges related to well-being and hygienic of the final product (4). Microbial pathogens transference to the products can be carried out during processing steps or from outer parts of the carcass (5). The removing of contamination or disinfection of the carcass 
body is hard to be realized by the use of a coadministered antimicrobial agent. In addition, commonly used antimicrobial and preservative substances possess artificial and alchemical properties, offering a lot of harmful effects and prospect hazards to consumer health (5).

Shrimp considered as one of the world's leading fishery products, especially in Egypt (6). The product is mainly exported under freezing conditions, passing through the shells and heads removing process (7). The economic value of raw shrimp shell substances and heads is little and they are considered as biological wastes or sold to factories of animal feeds (8). In the processing of shrimp industry, shrimp produce a large amount of biological waste, accounting for $45-55 \%$ of the raw weight of shrimp (9). Also, these biological wastes are able to be utilized in producing high-added value substances like chitosan and chitin. Chitosan, consisted of D-glucosamine units linked with $\beta$-linkage, is a cationic amino-polysaccharide which produced by partially deacetylation of chitin (10). If the acetyl- glucosamine groups proportions are higher (above 50\%), it is named chitin, however if the proportion is lower than $50 \%$, the ingredient is called chitosan $(11,12)$. The conventional methods for chitin extraction from crustaceans are chemical processes which involve the use of strong acid for demineralization and strong base for deproteination. However, these methods reduce the quality and increase the costs and environmental problems $(13,14)$. Chitosan can be characterized in terms of its quality, intrinsic properties (purity, molecular weight, viscosity, and degree of deacetylation) and physical forms (15).

In modern decades, microwave radiation has received considerable attention for its ability to speed up the reaction duration as compared to else procedures which transfer heat by conventional heating procedures, and can also perform heat transfer more uniformly in food compositions $(16,17)$. Therefore, the aim of the present study was to figure out the optimum conditions to get chitosan from chitin via microwave and to evaluate its physical properties, antioxidant and antimicrobial activities to determine the possibility of using this chitosan as preservatives in minced beef.

\section{Materials and methods}

\section{Materials and preparation of samples}

All chemical used in this study of HPLC grade (99.9\% purity) were obtained from Sigma company of chemicals and drugs, St. Louis, MO, USA. Wastes of shrimp (shells and heads) have been acquired from local restaurant in Kafr El-sheikh governorate, Egypt. The wastes were dried in an electric oven then were ground up to pass through 20 mesh screen sieve, the yielded powder samples were mixed, and stored in polyethylene bags, then kept at room temperature until use.

\section{Chemical composition}

Moisture, crude protein, ether extract, ash, crude fiber contents of investigated samples (shrimp waste, crude chitin and chitosan) were performed using the methods given in the (18).

\section{Isolation of chitin}

Various chitin extraction stages were carried out according to Synowiecki and Al-Khateeb (19). Demineralization process was operated by mixing $4 \mathrm{~g}$ shrimp waste with $40 \mathrm{ml}$ hydrochloric acid solution $2 \%(\mathrm{v} / \mathrm{v}$ ) for $12 \mathrm{hrs}$ at 30 ${ }^{\circ} \mathrm{C}$, and the mixture was centrifuged for $15 \mathrm{~min}$ at $4000 \mathrm{rpm}$, then the precipitate twice treated by distilled water. Deporteinization of the precipitate was operated by adding sodium hydroxide solution $4 \%(\mathrm{w} / \mathrm{v})$ to precipitate at liquid to solid ratio $(10: 1 \mathrm{v} / \mathrm{w})$ for $12 \mathrm{hrs}$ at $30^{\circ} \mathrm{C}$, and separation of different insoluble alkaline fractions by centrifugation for $15 \mathrm{~min}$ at 4000 $\mathrm{rpm}$, then was twice treated with distilled water and was dried overnight at $40^{\circ} \mathrm{C}$. The product obtained after drying was marked as pure chitin.

\section{Chitosan production via microwave route}

The various stages for chitosan production have been done as briefed via Sahu, et al. [13]. Chitosan was prepared from isolated chitin using various concentrations of sodium hydroxide aqueous solution $(\mathrm{NaOH} 30 \%, \mathrm{NaOH} 40 \%$ and $\mathrm{NaOH} 50 \%$ ) at several sample to solvent ratios 
$(1: 10,1: 15,1: 20$ and $1: 25)$ at different microwave power $(800 \mathrm{~W}, 900 \mathrm{~W}$ and $1000 \mathrm{~W})$ for various irradiation durations $(5,10,15$ and 20 minutes). chitosan yield recovered from each step was determined.

\section{Chemical, physical and functional attrib- utes for chitosan}

Extracted and commercial chitosan deacetylation grade was measured using the method of Qin et al., (20). Molecular weight and solubility of extracted and commercial chitosan were determined according to the method of (21). Water binding capacity and oil binding capacity of extracted chitosan sample were measured using the method of (22).

\section{Chitosan usage to preserve minced beef}

Fresh clean meat specimens were treated with the disinfectant sodium hypochlorite (100 $\mathrm{g}$ meat piece was soaked into $10 \mathrm{ppm}$ aqueous solution of sodium hypochlorite for $60 \mathrm{~min}$ followed by twice washes in distilled water). Pieces of meat were finely minced, blended and split to four groups. The first group (G1) untreated samples, G2 treated with $0.02 \%$ chitosan, G3 treated with $0.02 \%$ sorbistat-K, and G4 treated with a mixture of $0.01 \%$ chitosan and $0.01 \%$ sorbistat-K. All samples were stored at $5^{\circ} \mathrm{C}$ for seven days.

\section{Microbiological analyses}

Total count of aerobic microorganisms and fungi and yeasts were carried out at zero time and the end of storage period in triplicate as previously described (23).

\section{Sensory assessment}

After storage period, twenty semi-trained panelists from food technology department, kafrelshiekh University evaluated texture, color, and odour according to the method described by Pohlman, et al. (4).

\section{Statistical analysis}

All data (except phenolic content) were done in triplicate independent analyses and expressed as mean \pm standard deviation. Data of antibacterial activity were analyzed using one- way ANOVA according to (24) procedure. The significance level was set at $\mathrm{p} \leq 0.01$.

\section{Results and discussion}

\section{Chemical composition of shrimp waste}

Shrimp wastes were chemically analyzed for their contents of moisture, crude protein, ether extract, ash, crude fiber, total carbohydrates and the results were tabulated in Table (1). The data in Table (1) indicate that shrimp waste is considered a good source of protein, crude fiber and total carbohydrates which are important from the nutritional point of view. The results showed that the moisture, crude protein, ether extract, ash, crude fiber and total carbohydrate contents were $74.38,11.55,6.47,32.21,7.81$ and $41.96 \%$, respectively. These results were in harmony with those of $(25,26)$. Also, the data in the same table revealed that chitin content of shrimp wastes was $36.43 \%$ (on dry weight bases). According to the pervious results, shrimp wastes considered as a good source for chitin which can be modified to chitosan.

Production of chitosan by microwave

Effect of sodium hydroxide concentration

(\%) on chitosan yield

Table (2) shows the effect of using different concentrations (\%) of sodium hydroxide on the chitosan yield. The modification process by microwave heating was carried out using different concentrations of sodium hydroxide (30,40 and $50 \%$ ) at $800 \mathrm{~W}$ microwave power for $5 \mathrm{~min}$ and solid : liquid ratio (1:10). It could be observed that, there was an increment in chitosan yield as a function for increasing sodium hydroxide concentration. The highest chitosan yield (53.2\%) was obtained with $\mathrm{NaOH}$ concentration $(50 \%)$. These results were in harmony with those of (17).

\section{Effect of solid : liquid ratio on chitosan yield}

In this experiment, chitin modification process was carried out at $800 \mathrm{~W}$ microwave power for $5 \mathrm{~min}$ where, sodium hydroxide $(50 \%)$ was used as a solvent. The effect of solid: solvent ratio on chitosan yield was studied and the results were presented in Table (2). The results 
revealed that chitosan yield was significantly increased with increasing solid: liquid ratio from 1:10 to 1:20. Meanwhile, chitosan yield was decreased when solid: liquid ratio reached up 1:20. The decrement in chitosan yield after reaching the optimum condition of solid: liquid ratio may be due to the degradation effect of alkali solution on chitosan (27). From such results, it could be noticed that, the highest chitosan yield was obtained at 1:20 of sample: solvent ratio. Where at this ratio, the percent of chitosan yield was $67.4 \%$. These results are almost in agreement with those reported by (17).

\section{Effect of microwave power on chitosan yield}

In this experiment, chitin modification process was carried out using sodium hydroxide $(50 \%)$ as a solvent at 1:25 solid: liquid ratio for $5 \mathrm{~min}$. The effect of microwave power on chitosan yield was studied and the results were presented in Table (2). The results revealed that, chitosan decreased with increasing microwave power from 800 to 1000 . From such results, it could be noticed that, the highest chitosan yield was obtained at microwave power $(800 \mathrm{~W})$. At this microwave power; the percent of chitosan yield was $67.4 \%$. These results are in agreement with those found by (17). The obtained results may be due to thermal degradation of chitosan as a function to microwave power (28).

\section{Effect of using different modification peri- ods on chitosan yield}

In this experiment, the modification process of chitin was carried out using $800 \mathrm{~W}$ as microwave power, sodium hydroxide $(50 \%)$ as a solvent at 1:25 solid: liquid ratio for different periods $(5,10$ and $15 \mathrm{~min})$ and the results are illustrated in Table (2). The results indicated that, chitosan yield (\%) increased gradually with extending the modification time from 5 to $10 \mathrm{~min}$. This means that, the optimum period for chitin modification to chitosan was $10 \mathrm{~min}$. These results are in agreement with those found by (17). The previous results may be explained by (29) who reported that, prolonging the modification time after reaching the optimum time leads to degradation of chitosan and lost into the reaction solvent.

\section{Gross chemical composition of chitosan}

Table (3) show that, the total carbohydrates content of chitosan prepared from shrimp shell wastes was $89.11 \%$. It had low percentages of crude protein $0.98 \%$, ether extract $1.30 \%$, ash $0.31 \%$ and $2.21 \%$ crude fiber, respectively. Similar results were found by $(30,31)$. A high quality grade of chitosan should have less than $1 \%$ of ash content (32).

\section{Physicochemical and functional properties of chitosan}

The produced chitosan had a degree of deacetylation and molecular weight higher than commercial chitosan (Table 4). The deacetylation degree and molecular weight are important parameters for chitosan, as they affect its functional properties (33). The degree of deacetylation of chitosan is important for its application in the industry. Thus, certain researchers (34) suggested that the term chitosan should be used when the degree of deacetylation is above $70 \%$. Solubility, water holding capacity, oil holding capacity and intrinsic viscosity values of the produced chitosan were 94, 5.05, 3.21 and 10.13, respectively. Moreover, produced chitosan has water holding capacity and oil holding capacity compared with commercial chitosan. Our results were in the same line with those obtained by $(31,32)$.

\section{Using chitosan in minced beef preservation}

\section{Microbiological criteria}

The influence of adding chitosan and sorbistat-K into minced meat, on the amount of microorganisms, is presented in Figure 1. It was evidenced that the addition of $0.02 \%$ chitosan had the strongest effect for lowering the microbial count toward all examined microbial species. The combination of chitosan and sorbistat$\mathrm{K}$, at percentage of $0.01 \%$ from each, was the second strongest supplement, whereas the application of sorbistat-K was the weakest treatment to reduce microbial count. The total 
Table 1: Proximate chemical composition of shrimp waste (on dry weight basis)

\begin{tabular}{||l||l||}
\hline & Shrimp wastes \\
\hline \hline Moisture & 74.38 \\
\hline \hline Crude protein $(\mathrm{N} x$ 6.25) & 11.55 \\
\hline Ether extract & 6.47 \\
\hline Ash & 32.21 \\
\hline Crude fiber & 7.81 \\
\hline Total carbohydrates & 41.96 \\
\hline Chitin & 36.43 \\
\hline
\end{tabular}

Total carbohydrates were calculated by difference

Table 2: Effect of process variables on chitosan producing by microwave from shrimp waste

\begin{tabular}{lccccc}
\hline $\begin{array}{l}\text { Type of } \\
\text { experiment }\end{array}$ & Sodium hydroxide & Ratio & Time & Microwave & Chitosan yield \\
Concentration $(\%)$ & $($ sample/solvent $)$ & $($ min $)$ & power $(\mathrm{W})$ & $(\%)$
\end{tabular}

Sodium hydroxide concentration

$\begin{array}{lllll}30 & 1: 10 & 5 & 800 & 52.40 \\ 40 & 1: 10 & 5 & 800 & 52.80 \\ 50 & 1: 10 & 5 & 800 & 53.20\end{array}$

Sample/solvent ratio

$\begin{array}{ccccc}50 & 1: 10 & 5 & 800 & 53.20 \\ 50 & 1: 15 & 5 & 800 & 60.40 \\ 50 & 1: 20 & 5 & 800 & 67.40 \\ 50 & 1: 25 & 5 & 800 & 63.10\end{array}$

Microwave power

$\begin{array}{lcccc}50 & 1: 20 & 5 & 800 & 67.40 \\ 50 & 1: 20 & 5 & 900 & 60.40 \\ 50 & 1: 20 & 5 & 1000 & 54.80\end{array}$

Time

$\begin{array}{lcccc}50 & 1: 20 & 5 & 800 & 67.40 \\ 50 & 1: 20 & 10 & 800 & 69.83 \\ 50 & 1: 20 & 15 & 800 & 61.09\end{array}$

Table 3: Gross chemical composition Isolated chitosan

\begin{tabular}{|l|c||}
\hline Components \% & Samples \\
\hline Moisture & 8.30 \\
\hline \hline Crude protein $(\mathrm{N} x$ 6.25) & 0.98 \\
\hline Ether extract & 1.3 \\
\hline Ash & 0.31 \\
\hline Crude fiber & 2.21 \\
\hline Total carbohydrates & 89.11 \\
\hline \hline
\end{tabular}


Table 4: Physicochemical properties of prepared chitosan

\begin{tabular}{|l|c|c|}
\hline Components \% & Produced chitosan & Commercial chitosan \\
\hline Degree of deacetylation & 93 & 85 \\
\hline Molecular weight (k Daltons) & 4200 & 300 \\
\hline Solubility & 94 & 99 \\
\hline Water holding capacity & 5.05 & 3.12 \\
\hline Oil holding capacity & 3.21 & 1.56 \\
\hline Intrinsic viscosity & 10.13 & 15.92 \\
\hline
\end{tabular}

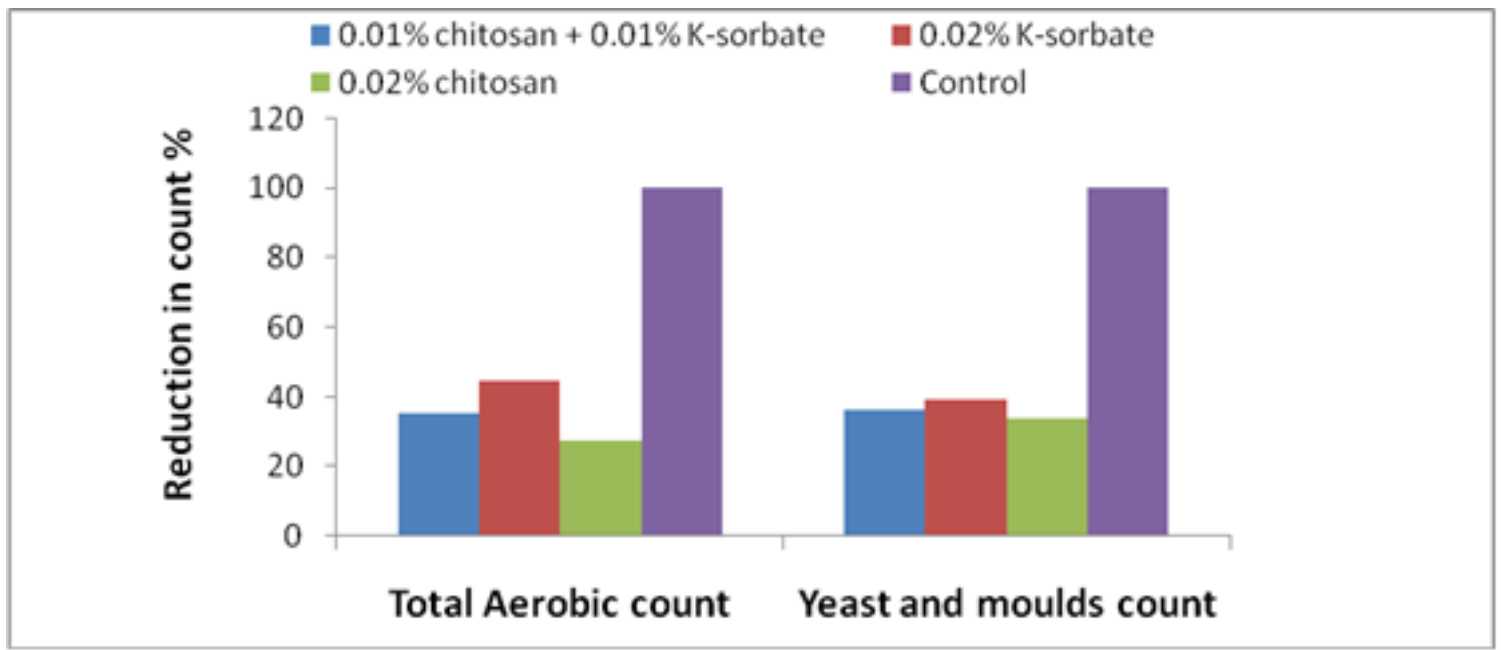

Figure 1: Effect of treating minced beef with chitosan and potassium sorbate on microbial count

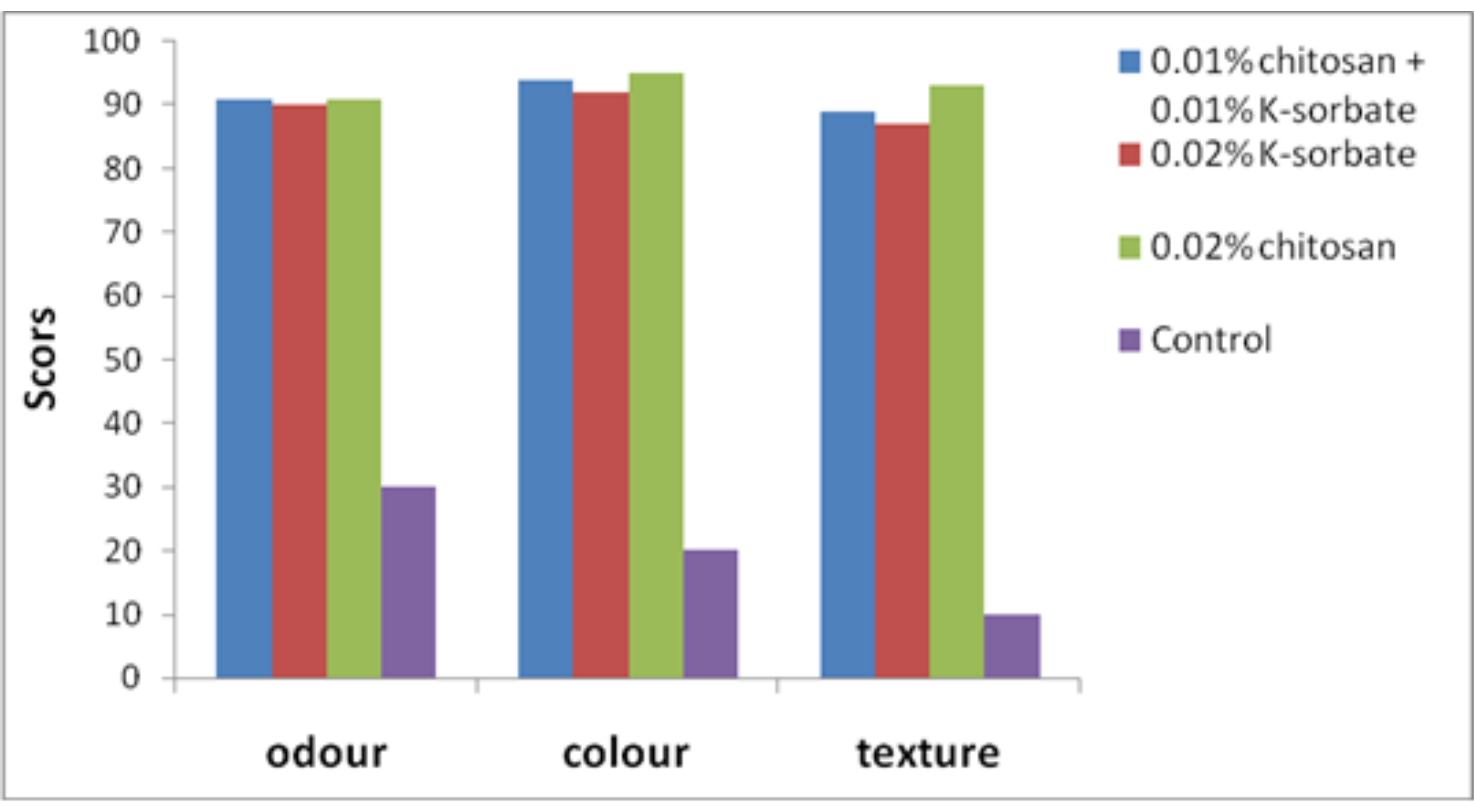

Figure 2: Effect of treating minced beef with chitosan and potassium sorbate on sensory characteristics 


\section{Sensory evaluation}

There was a significant improvement in the values of sensual attributes of minced beef as a result for usage of chitosan as a preservative. After ending the storage duration, the sensory attributes (e.g. colour, odour and texture) values of untreated beef samples were highly poor, compared with other samples contained chitosan or sorbistat-K (Fig. 2). Chitosan get a higher efficiency than sorbistat-K in maintaining meat texture and odour quality, whilst, meat samples integrated with sorbistat-K had the highest values in colour. The average for texture, odour and colour were 93.1,91.0 and $94.9 \%$ for $0.02 \%$ chitosan preserved meat; $87.1,89.9$ and $92.0 \%$ for $0.02 \%$ sorbistat-K and 9.9, 30.0 and $20.1 \%$ for control, respectively. Lipid auto-oxidation and myoglobin-oxidation are the essential reason for meat discoloration and oxidative rancidity or another un acceptable odour or flavour components (36). With minimizing the fat auto-oxidation level, there is a prospective that the deterioration in red meat colour will be minimized as they are related reactions (37).

\section{Conflict of interest}

The authors declare that they have no conflict of interest.

\section{References}

1. Pereira D, Pinheiro R S, Heldt L F S, Moura C d, Bianchin M, Almeida J d F, Ribeiro I S, Haminiuk C W I, Carpes S T. Rosemary as natural antioxidant to prevent oxidation in chicken burgers, Food Science and Technology (Campinas) 2017; 37(1): 17-23.

2. Nowak A, Czyzowska A, Efenberger M, Krala L. Polyphenolic extracts of cherry (Prunus cerasus L.) and blackcurrant (Ribes nigrum L.) leaves as natural preservatives in meat products, Food microbiology 2016; 59: 142-9.

3. Quevedo R, Pedreschi F, Valencia E, Díaz O, Bastías J, Muñoz O. Kinetic modeling of deterioration of frozen industrial burgers based on oxidative rancidity and color, Journal of Food Processing and Preservation 2018: e13655.

4. Pohlman F, Stivarius M, McElyea K, Johnson $\mathrm{Z}$, Johnson M. Reduction of microorganisms in ground beef using multiple intervention technology, Meat Science 2002; 61(3): 315-22.
5. Siragusa $\mathrm{G}$ r. The effectiveness of carcass decontamination systems for controlling the presence of pathogens on the surfaces of meat animal carcasses Journal of Food Safety 1995; 15(3): 229-38.

6. Sharawy Z Z, Thiele R, Abbas E M, El-Magd M A, Hassaan M S, Peter C, Schmidt J, Saborowski R, Goda A M A-S, Slater M J. Antioxidant response, body composition of whiteleg shrimp Litopenaeus vannamei co-cultured with Nile tilapia Oreochromis niloticus in recirculating aquaculture, Aquaculture Environment Interactions 2017; 9: 257-68.

7. Hirano K, Budiyanto E, Winarni S, Biological characteristics and forecasting outbreaks of the whitefly, Bemisia tabaci, a vector of virus diseases in soybean fields, ASPAC Food \& Fertilizer Technology Center1993.

8. Suchiva K, Chandrkrachang S, Methacanon P, Peter M. Proceedinggs of the 5th Asia Pacific Chitin and Chitosan Symposium \& Exhibition, Bangkok, Thailand 2002.

9. Lertsutthiwong P, How N C, Chandrkrachang S, Stevens W F. Effect of Chemical Treatment on the Characteristics of Shrimp Chitosan, Journal of Metals, Materials and Minerals 2002; 12(1): 11-8.

10. Elkeiy M, Khamis A, El-Gamal M, Abo Gazia M, Zalat Z, El-Magd M. Chitosan nanoparticles from Artemia salina inhibit progression of hepatocellular carcinoma in vitro and in vivo, Environ Sci Pollut Res Int. doi: 10.1007/s11356-018-3339-6 2018.

11. Kamboj S, Singh K, Tiwary A, Rana V. Optimization of microwave assisted Maillard reaction to fabricate and evaluate corn fiber gumchitosan IPN films, Food Hydrocolloids 2015; 44 : 260-76.

12. Thakur V K, Voicu S I. Recent advances in cellulose and chitosan based membranes for water purification: a concise review, Carbohydrate polymers 2016; 146: 148-65.

13. Sahu A, Goswami P, Bora U. Microwave mediated rapid synthesis of chitosan, Journal of Materials Science: Materials in Medicine 2009; 20(1): 171-5.

14. Younes I, Rinaudo M. Chitin and chitosan preparation from marine sources. Structure, properties and applications, Marine drugs 2015; 13(3): 1133-74.

15. Berger J, Reist M, Chenite A, Felt-Baeyens O, Mayer J, Gurny R. Pseudo-thermosetting chitosan hydrogels for biomedical application, International journal of pharmaceutics 2005; 288(2): 197-206. 
16. Alishahi A, Mirvaghefi A, Tehrani M, Farahmand H, Koshio S, Dorkoosh F, Elsabee M Z. Chitosan nanoparticle to carry vitamin $\mathrm{C}$ through the gastrointestinal tract and induce the non-specific immunity system of rainbow trout (Oncorhynchus mykiss), Carbohydrate polymers 2011; 86(1): 142-6.

17. El-Mahdy S S, Hayam F, Abd El-Wanis N, Hamoud M. Comparative studies between different commercial types of live infectious bursal disease [IBD] vaccine strains in Egypt, American Journal of Research Communication 2013; 1(10): 113-29.

18. A.O.A.C. Association of Official of Analytical Chemists, Official Methods of Analysis. 18th Ed., Pub. By the A.O.A.C., Arlington, Virginia, 2220 USA., (2010).

19. Synowiecki J, Al-Khateeb N A A Q. Mycelia of Mucor rouxii as a source of chitin and chitosan, Food Chemistry 1997; 60(4): 605-10.

20. Qin C, Li H, Xiao Q, Liu Y, Zhu J, Du Y. Water-solubility of chitosan and its antimicrobial activity, Carbohydrate polymers 2006; 63(3): 367-74.

21. Fernandez-Kim S-O. Physicochemical and functional properties of crawfish chitosan as affected by different processing protocols, 2004.

22. Sciarini L, Maldonado F, Ribotta P, Pérez G, León A. Chemical composition and functional properties of Gleditsia triacanthos gum, Food Hydrocolloids 2009; 23(2): 306-13.

23. Georgantelis D, Blekas G, Katikou P, Ambrosiadis I, Fletouris D J. Effect of rosemary extract, chitosan and $\alpha$-tocopherol on lipid oxidation and colour stability during frozen storage of beef burgers, Meat Science 2007; 75(2): 256-64.

24. Steel R G, Torrie J H, Dickey D A. Principles and procedures of statistics: A biometrical approach. McGraw-Hill, New York, Principles and procedures of statistics: A biometrical approach. 2nd ed. McGraw-Hill, New York. 1980: -.

25. Kim S E, Park J H, Cho Y W, Chung H, Jeong S Y, Lee E B, Kwon I C. Porous chitosan scaffold containing microspheres loaded with transforming growth factor- $\beta 1$ : implications for cartilage tissue engineering, Journal of Controlled Release 2003; 91(3): 365-74.

26. Ushakumari U N, Ramanujan R. Astaxanthin from shrimp shell waste, International journal of pharmaceutical chemistry research 2012; 1(3): 1-6.

27. Mourya V, Inamdar N N. Chitosanmodifications and applications: opportunities galore, Reactive and Functional polymers 2008; 68(6): 1013-51.

28. Luo J, Wang X, Xia B, Wu J. Preparation and characterization of quaternized chitosan under microwave irradiation, Journal of Macromolecular Science, Part A: Pure and Applied Chemistry 2010; 47(9): 952-6.

29. Al Sagheer F, Al-Sughayer M, Muslim S, Elsabee M. Extraction and characterization of chitin and chitosan from marine sources in Arabian Gulf, Carbohydrate Polymers 2009; 77(2): 410-19.

30. Khan T A, Peh K K, Ch'ng H S. Reporting degree of deacetylation values of chitosan: the influence of analytical methods, J Pharm Pharmaceut Sci 2002; 5(3): 205-12.

31. Kucukgulmez A, Celik M, Yanar Y, Sen D, Polat H, Kadak A E. Physicochemical characterization of chitosan extracted from Metapenaeus stebbingi shells, Food Chemistry 2011; 126(3): 1144-8.

32. No H K, Meyers S P. Preparation and characterization of chitin and chitosan - a review, Journal of aquatic food product technology 1995; 4(2): 27-52.

33. Rout S K. Physicochemical, Functional and Spectroscopic Analysis of Crawfish Chitin and Chitosan as Affected by Process Modification, 2001.

34. Li Q, Dunn E, Grandmaison E, Goosen M F. Applications and properties of chitosan, Journal of Bioactive and Compatible Polymers 1992; 7(4): 370-97.

35. Moussa S H, Tayel A A, Al-Hassan A A, Farouk A. Tetrazolium/formazan test as an efficient method to determine fungal chitosan antimicrobial activity, Journal of Mycology 2013; 2013.

36. Chan W K, Faustman C, Decker E A. Oxymyoglobin oxidation as affected by oxidation products of phosphatidylcholine liposomes, Journal of Food Science 1997; 62(4): 709-12.

37. Brand-Williams W, Cuvelier M-E, Berset C. Use of a free radical method to evaluate antioxidant activity, LWT-Food science and Technology 1995; 28(1): 25-30. 